\title{
Profile and Motivation of Patients Consulting in Emergency Departments While not Requiring Such a Level of Care
}

\author{
Daniel Aiham Ghazali ${ }^{1,2,3,4, * \mathbb{D}}$, Arnaud Richard ${ }^{1,2}$, Arnaud Chaudet ${ }^{5}$, Christophe Choquet ${ }^{1,2}$, \\ Maximilien Guericolas ${ }^{1,2}$ and Enrique Casalino ${ }^{1,2,4}$ \\ 1 Emergency Department, University Hospital of Bichat, 75018 Paris, France \\ 2 Study Group for Efficiency and Quality of Emergency Departments and Non-scheduled Activities \\ Departments, 75018 Paris, France \\ 3 Simulation Center, University of Paris Diderot, 75018 Paris, France \\ 4 INSERM UMR 1137, IAME, University of Paris Diderot, 75018 Paris, France \\ 5 Emergency Department, University Hospital of Poitiers, 86000 Poitiers, France \\ * Correspondence: aiham@hotmail.com
}

Received: 20 September 2019; Accepted: 4 November 2019; Published: 12 November 2019

check for updates

\begin{abstract}
Consultations that do not require an emergency department (ED) level of care have increased. We explored attitudes of non-urgent patients in two academic hospitals in France with a similar fast track organization. One of them is a Parisian hospital with 90,000 patients/year who are admitted to the ED, while the other admits 40,000 patients/year in a smaller city. During one month in 2018, the triage nurse handed out a survey to patients coming for non-urgent consultations. It was given back to the fast track physician at the end of the visit; 598 patients agreed to answer. They were mostly young males with adequate social coverage, consulting for osteo-articular pathologies, without any significant difference between the two sites $(p=0.32)$. They were equally satisfied with the care they received $(p=0.38)$. Satisfaction was inversely correlated to waiting time $(p<0.0001)$. Convenience, accessibility of emergency facilities, and geographic proximity were motivation factors. These results suggest that primary care providers who can access testing facilities in accordance with patient needs might be a solution to help reduce overcrowding in EDs.
\end{abstract}

Keywords: emergency department; non-urgent consult; profile; motivation; overcrowding

\section{Introduction}

Definition of a Consultation not Requiring a Medical Emergency Department Level of Care

Many patients who consult at an emergency department (ED) do not require immediate diagnosis or treatment, and therefore do not require care in an ED. Data on these patients throughout literature are very heterogeneous due to the absence of a consensus on how to define these particular patients. The literature review by Durand et al. highlighted the confusion between consultations considered non-urgent and those considered inappropriate [1]. The concept of a non-urgent consultation is tied to the severity of the pathology, speed of evolution, or need for hospitalization or not. The concept of an inappropriate consult is tied to the social and psychological context on top of the medical issue, and must integrate factors such as visiting hours and availability of healthcare services in the vicinity of the ED [1]. It, therefore, seems more appropriate to use the terminology of consultations not requiring an ED level of care that are manageable in a primary care setting.

Non-urgent visits to EDs are a controversial issue as they have been negatively associated with crowding and cost [1]. A steady increase in health-establishment-based ED visits has been observed 
in France. Since 2002, EDs have reported a 40\% to 50\% increase in visits [2]. This increase cannot be attributed solely to demographic growth or to an aging population. Some patients, particularly homeless people, migrants, refugees, and asylum seekers, have difficulty choosing between different means of access to health services. Despite the crisis in Europe in 2008, immigration has increased by $2 \%$ per year [3]. This phenomenon has been accentuated in Europe, including France, due to wars in the Middle East and Africa. Over recent years, there has been a 35\% increase of asylum seekers in Europe [4]. There exist differences in healthcare service utilization between immigrant and native populations [5]. In France, for both cultural and administrative reasons, social analyses by ethnic origin are not routinely carried out [6]. However, immigrants present a lower demand for GP and specialist care [7]. In Europe, they seem to more frequently prefer emergency healthcare services than native born patients $[4,5]$. Unfortunately, accurate registration regarding healthcare services provided to undocumented migrants is largely lacking. Nevertheless, a recent systematic review showed that they tended to underutilize several types of healthcare services [8].

The volume of consultations not requiring an ED level of care has increased in other developed countries [9]. These "inappropriate" consultations represent $10 \%$ to $90 \%$ of all visits, with a median of $32 \%$ [1]. Non-urgent ED visits are a major problem in several countries, including Kuwait (61\%), Cuba $(57.9 \%)$, and Hong Kong (57.0\%). In other countries they are moderate, such as Germany $(49.9 \%)$, Great Britain (40.9\%), Sweden (38.3\%), France (31.7\%), Portugal (31.3\%), and Turkey (31.2\%). In still other countries they are less prevalent, such as the United States (12.5\%), Italy (19.6\%), Brazil (24.2\%), Canada (25\%), and Spain (29.6\%). This spread is due to the absence of a universal definition for "non-urgent consultations". These visits are all the more "inappropriate" because the majority of them occur during the business hours of most primary care providers (PCP) [10], for the most part at the sole initiative of the patient $[1,2,11-13]$. Personal convenience and ease of emergency care use were listed as motivations for consulting ED in several countries, such as Japan [14], the United States [15], and Spain [16]. This influx of non-severe patients does not benefit from the holistic management that a general practice provides and it increases the already growing number of ED consultations caused by an aging population and a rise in chronic illnesses [17].

This growing phenomenon can be partially explained by the organization of general practices (generalization of appointment-only consultation, growth of part-time employment) [18] and also by the insufficient capacity of private practices [19]. There exists a communicating vessel effect between the decrease in non-urgent health structures providing outpatient care and the care provided by EDs, despite the high activity levels of the aforementioned structures $[18,20]$. This dysfunctional pathway to primary care produces a heavy economic burden for our society [18]. However, the issue is considerably more complex. It is important to know why these patients choose to consult at an ED rather than with their PCP. Scientific literature details several reasons for "inappropriate" consultations at an ED: unavailable PCP [2,12,21-24], changes in patient behavior regarding primary care access [2,25], patient determination to have additional biological testing or imagery [25,26], lower socio-economic status [27], and unwillingness to pay up front $[28,29]$. This information could help to determine whether it could be suggested to patients on arrival at the ED to consult their PCP without having been examined by an ED physician.

The aim of this study was to analyze the profiles, motivations, and post-ED consult satisfaction of patients not requiring ED consultation. The aim was also to determine whether it is possible to redirect patients to a PCP before consulting with the emergency physician based on a potential initial triage error. We hypothesized that improved understanding of these patients could lead to appropriate action while stemming the ever-increasing flow of ED patients in France. Characterization of these patients in different environments with different care offerings would provide better understanding of the expectations that lead them to come to the ED. Therefore, based on this characterization and on the potential risk of redirecting patients, we would be able to determine whether an alternative solution is really possible or not without risk to the patient. 


\section{Methods}

\subsection{Study Design}

We performed a prospective multicentric study in the ED of Bichat University Hospital in Paris (France) from March 13 until April 16, 2018. This study was also conducted in the ED of Poitiers University Hospital from June 11 until August 5. Each patient consulting an ED in France is ranked by a triage nurse (TN) using the French Emergency Nurses Classification in Hospital scale (CIMU) (Appendix B) [30]. The least severe patients are ranked as CIMU 5, meaning that there is no functional impairment or organic lesion justifying the use of hospital resources. These two sites were chosen because they are in towns with different sizes and locations. However, their organizational structures are comparable insofar as they both use a fast track that is isolated from the rest of the ED for CIMU 5 patients.

\subsection{Objectives}

The primary objective of this study was to determine the profile of CIMU 5 patients consulting the ED, including sociodemographic characteristics, health service access, and reasons for consulting at an ED.

Secondary objectives were to:

- Establish whether CIMU 5 patients could be reoriented by the TN towards their PCP without an ED physician consultation;

- Assess post-ED consultation satisfaction.

\subsection{Population}

In the Bichat University Hospital ED, an average of 250 patients present themselves for consultation each day (90,000 patients per year). Close to one-third of them leave the ED without any further testing or immediate treatment. The hospital is located in the 18th district of Paris, with a population in 2015 of 199,135; it is an urban area suffering from a lack of general practitioners, with 6.5 PCPs per 10,000 inhabitants, with lows of 5.5 and 2.9 PCPs in some of the poorer sectors in 2013 [31]. This is in contrast to the national average of 8.9 PCPs per 10,000 inhabitants in 2016 [32]. In Paris, there are 39 university hospitals, two of which are in the 18th district: Bichat and Bretonneau. In this district, only Bichat has a 24-hour-a-day emergency department. There are also private emergency departments in Paris. Poitiers University Hospital is located in a small city (87,918 inhabitants in 2015). An average of 120 patients are admitted to the ED each day (44,000 per year). There are 126 PCPs in the city, which is a high density at 14.3 PCPs per 10,000 inhabitants. Only the university hospital and a private clinic provide a 24-hour-a-day ED.

Inclusion criteria of patients were:

- $\quad$ Age > 18 years;

- Beneficiary of social security;

- French or English speaking and writing;

- French resident;

- Spontaneously coming to consult at the emergency department; in other words, not having been sent to the ED by the 112 emergency hotline, another physician, or brought to the ED by any first responder (police, fire department, military);

- $\quad$ Categorized as CIMU 5.

Exclusion criteria were:

- Having been asked back by the ED (systematic follow-up, clinical deterioration);

- Unable to write (for example, due to trauma); 
- Vulnerable or marginalized members of the population (homeless, refugees, migrants, undocumented migrants, etc.);

- Presenting with a nonmedical issue;

- Having refused to participate in the study;

- Having answered the survey but having left without having been seen by the ED physician;

- Not categorized as CIMU 5 (in case of survey given to the wrong patient);

- Other cases (inaccurate history).

\subsection{Questionnaire}

A survey (Appendix A) was built to gather the required data. Its structure is based on the literature. These findings were validated by a committee of experts using the Delphi method, wherein questions were added, removed, or modified until a consensus of at least $65 \%$ agreement was reached [33]. After discussion with the experts during the Delphi process, we voluntarily focused only on patients who had the possibility of consulting elsewhere than in an ED. Presently, France is facing major immigration-related social challenges, but the solution as it pertains to healthcare cannot be found only at the ED level, and requires social and political considerations. Barriers to access to health services are thought to include education, cultural differences, language difficulties, lack of complementary voluntary health insurance, and legal issues [6].

\subsection{Data Collection}

The TN handed out a survey (in French or English) to the included CIMU 5 patients so they could answer it while waiting for their medical consultation. The completed survey was given back to the fast track physician at the end of the visit and the patients were asked about their satisfaction level. Additional clinical data were extracted from the digital patient record using M-UrQual ${ }^{\circledR}$ software (Maincare Solutions, Cestas, France) in the Bichat Hospital ED and ResUrgences ${ }^{\circledR}$ software (Berger Levrault, Boulogne-Billancourt, France) in the Poitiers Hospital ED, including the medical ranking of clinical severity. The patients were contacted by phone 15 days after their ED visit, between 18:00 and 20:00, to collect information about their status once having left the ED and their satisfaction level. We called a given patient 3 times on separate days before considering the person as "non-respondent".

\subsection{Flow Chart}

At the Bichat University Hospital, 412 patients met the inclusion criteria. They represented $5.2 \%$ of the overall activity at the ED. Overall, 260 agreed to answer. Of these, 17 were excluded for various reasons. In total, 243 surveys were gathered, representing a 59.0\% answer rate (Figure 1). At the Poitiers University Hospital, 557 patients were included in the study. They represented $8.7 \%$ of the total ED activity. Overall, 370 agreed to answer the survey. Of these, 15 were excluded for various reasons. In total, 335 surveys were gathered, representing a 63.7\% response rate. Overall, 598 surveys were studied (Figure 1). 


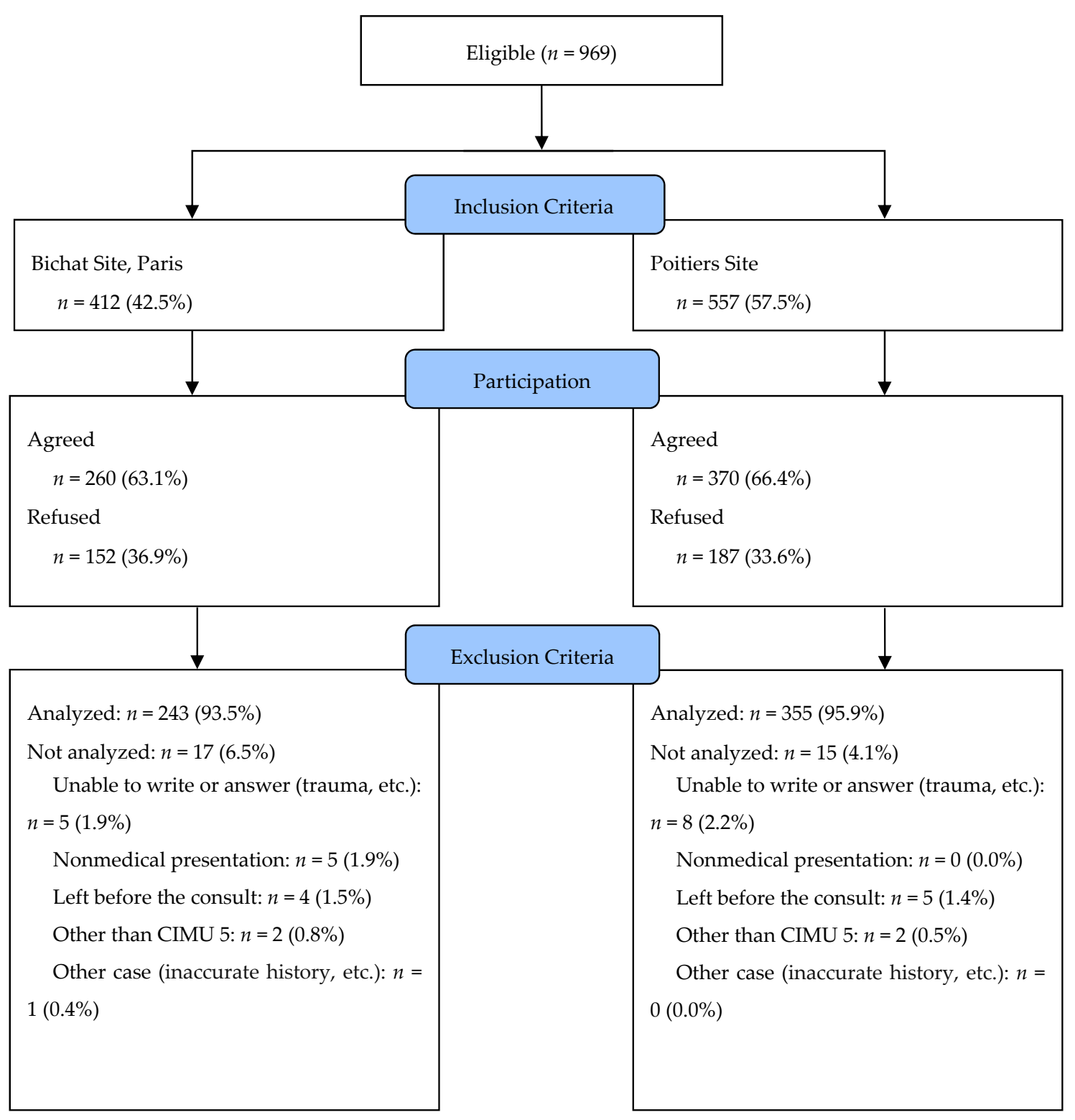

Figure 1. CONSORT (Consolidated Standards of Reporting Trials) 2010 Flow Chart.

\subsection{Outcomes and Study Variables}

The clinical severity of CIMU 5 patients was compared with the French emergency department medical clinical classification (classification clinique médicale des urgences, CCMU) [34]. It is used to evaluate the severity of the patient at the end of the clinical examination (Appendix $C$ ). We assumed that CIMU 5 patients would be classified less than CCMU 3 (presentation likely to deteriorate without life-threatening prognosis). Patient satisfaction after having left the ED was studied through a Likert 5-level scale (very unsatisfied, unsatisfied, no opinion, satisfied, very satisfied). Variables assessed in the survey (Appendix B) were demographic data (sex, age), place of residence, social security coverage, PCP or not, and professional status as defined by the French National Institute of Statistics and Economic Studies (INSEE), including 8 categories of work and a student category. Number of visits to an ED per year, reason for consulting, date of onset of symptoms, consultation at PCP or other doctor's office, and motivation to visit an ED were also assessed. 


\subsection{Statistics}

Statistical analysis was carried out with the Statview ${ }^{\circledR}$ version 4.5 application (SAS Institute Inc., Cary, NC, USA) and Excel 2016 ${ }^{\circledR}$ (Microsoft, Redmond, WA, USA). Sample size calculation was based on the comparison of an assumed observed proportion of $2 \%$ CCMU 3 or more among the CIMU 5 patients, with theoretical CIMU 5 patients classified as CCMU 1 or 2 . Number of patients to include was estimated at 206 in each center, based on an alpha risk of 0.05 , a statistical power of 0.95 , and using unilateral tests. Taking into account refusals of participation, exclusions, and unusable data, we assumed that it was necessary to recruit twice the estimated number of patients (i.e., 412). The daily flow of ED visits to Bichat is twice that of Poitiers. We hypothesized that at least one month would be necessary to carry out the study in the Bichat ED and two months in the Poitiers ED. The normality of the distribution for each parameter was explored using the Kolmogorov-Smirnov test. Continuous variables were described using means and standard deviations or medians and first and third quartiles (Q1, Q3). Categorical variables were described using population count and corresponding percentage for each modality. Continuous variables were compared to one another using the Student $t$ test or a nonparametric Mann-Whitney $U$ test if necessary. Comparisons between several categorical variables were carried out using the nonparametric Kruskal-Wallis test due to small sample sizes. Categorical variables were compared one-to-one with a Chi-square test. A Spearman test (rho) was used for correlation analysis.

A $p$-value $<0.05$ was considered statistically significant.

\subsection{Ethics}

The patients were informed of the study, of it being optional, and of the anonymization of the answers at every step (when the surveys were handed out and during the follow-up phone call). Data collection was done with every survey handed out to each patient. The phone numbers collected in the surveys allowed us to contact the patients afterwards. This procedure was accepted by the Commission Nationale de l'Informatique et des Libertés (CNIL) and the Emergency Department committee on ethics, research, and informatics (IRB number U-2017-4.2). The informed consent form is shown in Appendix D. Research was performed in accordance with the Declaration of Helsinki. The local ethics committee of the University Hospital of Poitiers approved this research. Participants consented to participate.

\section{Results}

\subsection{CIMU 5 Patient Characteristics}

A clear majority of the participants were men, who represented $79.4 \%(n=179)$ of the patients. The median age was 38 years (interquartile range: $27 ; 50)$. In $52.1 \%$ of all cases $(n=314)$, they lived near the ED (less than $15 \mathrm{~km}$ and less than 20 minutes away by car or mass transit). For $70.7 \%$ of patients $(n=432)$, the PCP was near the hospital. In total, $85.5 \%$ of the patients $(n=511)$ were covered by social security, while $66.1 \%$ of patients $(n=395)$ also had complimentary health coverage. Additionally, $87.1 \%$ of patients $(n=521)$ declared a principal PCP. The socio-economic category "employee" was the most widely present at 33.9\% $(n=203)$, followed by the unemployed, who represented $14.9 \%(n=89)$. Characteristics and comparisons between the Bichat and Poitiers sites are presented in Table 1.

\subsection{Patient Flow Paths}

Patient flow paths median time between symptom onset and ED consult was 2 days (interquartile range: $1 ; 7$ ) at Bichat, and 1 day (interquartile range: $1 ; 6)$ at Poitiers. The maximum delay was 730 days for a patient of Bichat suffering from chronic back pain. This patient was excluded from the study because of possibly inaccurate history. At Bichat, only $16.5 \%(n=40)$ of patients had consulted a doctor before coming to the ED, whereas $43.9 \%(n=156)$ had done so at Poitiers $(p<0.0001)$. At Bichat, $86.0 \%$ $(n=209)$ of consultations occurred during hours of the day when private practice alternatives were 
available. At Poitiers, $81.7 \%$ of patients $(n=290)$ consulted during hours of the day when private practice alternatives are available, which was comparable to Bichat $(p=0.16)$. Detailed analyses of the total population and for each hospital for the days and schedules of consultations according to whether or not a PCP was reported are given in Table 2. Patients having a PCP or not consulted similarly during business hours $(p=0.57)$. Additionally, having a PCP did not influence the choice of consulting, either during the week or during the weekends and holidays $(p=0.58)$. There was no difference in behavior between patients who reported or did not report a PCP in both hospitals, either in terms of days or of hours of consultation.

Table 1. Characteristics of patients who did not require an emergency department (ED) level of care.

\begin{tabular}{|c|c|c|c|c|}
\hline Characteristics of Patients & $\begin{array}{c}\text { Total } \\
n=598\end{array}$ & $\begin{array}{c}\text { Bichat } \\
n=243\end{array}$ & $\begin{array}{c}\text { Poitiers } \\
n=355\end{array}$ & $p$ \\
\hline Male patients, no. (\%) & $475(79.4)$ & $179(73.7)$ & $296(83.4)$ & 0.003 \\
\hline Age (year), median (IQR *) & $38(27-50)$ & $37(27-50)$ & $38(26-49)$ & 0.74 \\
\hline Nearby place of residence ${ }^{* *}$, no. $(\%)$ & $314(52.5)$ & $140(57.6)$ & $174(49.0)$ & 0.04 \\
\hline Basic Social Security coverage, no. (\%) & $511(85.5)$ & $200(82.3)$ & $311(87.6)$ & 0.07 \\
\hline Complementary health coverage, no. (\%) & $395(66.1)$ & $142(58.4)$ & $253(81.4)$ & 0.04 \\
\hline Designated primary care provider, no. (\%) & $521(87.1)$ & $189(77.8)$ & $332(93.5)$ & $<0.0001$ \\
\hline Nearby primary care provider, no. (\%) & $423(70.7)$ & $215(88.5)$ & $208(58.6)$ & $<0.0001$ \\
\hline \multicolumn{5}{|l|}{ Professional category/occupation, no. (\%) } \\
\hline Farmers & $5(0.8)$ & $1(0.4)$ & $4(1.1)$ & \multirow{9}{*}{0.27} \\
\hline Managers & $50(8.4)$ & $29(11.9)$ & $21(5.9)$ & \\
\hline Craftsman/woman & $33(5.5)$ & $10(4.1)$ & $23(6.5)$ & \\
\hline Laborers & $48(8.0)$ & $21(8.6)$ & $27(7.6)$ & \\
\hline Middle management & $41(6.9)$ & $7(2.9)$ & $34(9.6)$ & \\
\hline Employees & $66(11.0)$ & $22(9.1)$ & $44(12.4)$ & \\
\hline Inactive & $89(14.9)$ & $39(16.1)$ & $50(14.1)$ & \\
\hline Students & $203(33.9)$ & $86(35.4)$ & $117(32.9)$ & \\
\hline Retired & $63(10.6)$ & $28(11.5)$ & $35(9.9)$ & \\
\hline
\end{tabular}

Note: ${ }^{*}$ IQR: interquartile range; ${ }^{* *}<15 \mathrm{~km}$ and $<20$ min away from the hospital by personal vehicle or by mass transit.

Table 2. Day and time of consultations not requiring an ED level of care.

\begin{tabular}{|c|c|c|c|c|c|c|c|c|c|}
\hline & \multicolumn{3}{|c|}{ Total of CIMU $5 *$ Patients } & \multicolumn{3}{|c|}{ University Hospital of Bichat } & \multicolumn{3}{|c|}{ University Hospital of Poitiers } \\
\hline & PCP ** & No PCP & $p$ & PCP & No PCP & $p$ & PCP & No PCP & $p$ \\
\hline 08:00-20:00 & 433 & 66 & \multirow{2}{*}{0.57} & 161 & 48 & \multirow{2}{*}{0.48} & 272 & 18 & \multirow{2}{*}{0.66} \\
\hline 20:00-08:00 & 88 & 11 & & 28 & 6 & & 60 & 5 & \\
\hline Weekdays & 363 & 56 & \multirow[b]{2}{*}{0.58} & 145 & 40 & \multirow[b]{2}{*}{0.69} & 218 & 16 & \multirow{2}{*}{0.15} \\
\hline Weekends/Holidays & 158 & 21 & & 44 & 14 & & 114 & 7 & \\
\hline
\end{tabular}

Note: * CIMU: The French Emergency Nurses Classification in Hospital scale (CIMU 5: no functional impairment or organic lesion justifying the use of hospital resources); ${ }^{* *} \mathrm{PCP}:$ primary care provider.

\subsection{Complaints Justifying the Consultations}

All the complaints were sorted out using the French Emergency Medicine Society (SFMU) classification shown in Table 3. There was no difference between the two sites when the categories were compared globally $(p=0.32)$. Osteo-articular pathologies, including rheumatology and traumatology reasons for consultation, were relatively predominant, accounting for $38.3 \%(n=93)$ of the total at Bichat and $31.5 \%(n=112)$ at Poitiers $(p=0.09)$. Nevertheless, comparison of categories shows that some complaints were voiced at a significantly different rate at the two sites. For instance, at Bichat, gastro-intestinal complaints were more frequent than at Poitiers $(p<0.0001)$, whereas ophthalmological and ear, nose, and throat (ENT) complaints were brought up more frequently at Poitiers $(p<0.0001$ and $p=0.02$, respectively). The primary reason for consulting for women was skin issues (29 out of 123 women, or $23.6 \%$ ), whereas for men it was trauma (62 out of 475 men, or 13.1\%). The different reasons for patients to consult at an ED are shown in Table 4. There were no differences between the 
sites in global comparison of reasons for consultation $(p=0.29)$. The main factor that brought the surveyed patients to consult at an ED was the expectation of getting hospital-based care, including access to further testing or hospitalization. This expectation was shared by $26.8 \%(n=65)$ of Bichat patients and by $29.9 \%(n=106)$ of Poitiers patients $(p=0.68)$. Patients consulting for traumatology significantly more frequently expected additional testing or imagery than other patients $(p=0.003)$. The proportion of patients mentioning personal convenience (geographic proximity, opening hours) as a justification to consult at an ED differed between the sites. This type of reason concerned $30.9 \%$ $(n=75)$ of Bichat patients and $20.2 \%(n=72)$ of Poitiers patients $(p=0.003)$. The French health system allows patients not to pay for their care up front after having visited an ED, which is sometimes the case in the private sector. The reasoning of not having to pay on the day of consultation was given by only $5.3 \%(n=13)$ of Bichat patients and $2.0 \%(n=7)$ of Poitiers patients. The difference between the two sites was significant $(p=0.02)$. In France, the existing system actually encourages patients to be managed in an ED in cases of workplace accidents if they come by ambulance. However, in other cases they have the possibility to consult a PCP. Consequently, "workplace accident" does not systematically mean urgent care for the emergency staff.

Table 3. Consultation reasons given by CIMU 5 * patients as categorized by SFMU **.

\begin{tabular}{lcccc}
\hline \multicolumn{1}{c}{ Consultation Reasons } & $\begin{array}{c}\text { Total } \\
\boldsymbol{n}=\mathbf{5 9 8}\end{array}$ & $\begin{array}{c}\text { Bichat } \\
\boldsymbol{n}=\mathbf{2 4 3}\end{array}$ & $\begin{array}{c}\text { Poitiers } \\
\boldsymbol{n}=\mathbf{3 5 5}\end{array}$ & $\boldsymbol{p}$ \\
\hline Cardio-vascular, no. (\%) & $26(4.3)$ & $13(5.3)$ & $13(3.7)$ & 0.32 \\
Dermatological, no. (\%) & $74(12.4)$ & $23(9.5)$ & $51(14.4)$ & 0.07 \\
Gastroenterological, no. (\%) & $43(7.2)$ & $30(12.4)$ & $13(3.7)$ & $<0.0001$ \\
General and other, no. (\%) & $58(9.7)$ & $30(12.4)$ & $28(7.9)$ & 0.07 \\
Urogenital, no. (\%) & $24(4.0)$ & $13(5.3)$ & $11(3.1)$ & 0.17 \\
Neurological, no. (\%) & $28(4.7)$ & $10(4.1)$ & $18(5.1)$ & 0.59 \\
Ophthalmological, no. (\%) & $57(9.5)$ & $4(1.6)$ & $53(14.9)$ & $<0.0001$ \\
ENT, no. (\%) & $67(11.2)$ & $18(7.4)$ & $49(13.8)$ & 0.02 \\
Psychiatry, no. (\%) & $7(1.2)$ & $4(1.6)$ & $3(0.8)$ & 0.45 \\
Respiratory, no. (\%) & $9(1.5)$ & $5(2.1)$ & $4(1.1)$ & 1 \\
Rheumatology, no. (\%) & $109(18.2)$ & $49(20.2)$ & $60(16.9)$ & 0.31 \\
Traumatology, no. (\%) & $96(16.1)$ & $44(18.1)$ & $52(14.6)$ & 0.26 \\
\hline
\end{tabular}

Note: ${ }^{*}$ CMIU: The French Emergency Nurses Classification in Hospital scale (CIMU 5: no functional impairment or organic lesion justifying the use of hospital resources); ${ }^{* *}$ SFMU: French Society of Emergency Medicine.

Table 4. Motivation of patients without functional impairment or organic lesion justifying the use of hospital resources for consulting an ED.

\begin{tabular}{lcccc}
\hline \multicolumn{1}{c}{ Motivation } & $\begin{array}{c}\text { Total } \\
\boldsymbol{n}=\mathbf{5 9 8}\end{array}$ & $\begin{array}{c}\text { Bichat } \\
\boldsymbol{n}=\mathbf{2 4 3}\end{array}$ & $\begin{array}{c}\text { Poitiers } \\
\boldsymbol{n}=\mathbf{3 5 5}\end{array}$ & $\boldsymbol{p}$ \\
\hline Workplace accident, no. (\%) & $17(2.8)$ & $6(2.5)$ & $11(3.1)$ & 0.65 \\
Suggested by peers, no. (\%) & $3(0.5)$ & $1(0.4)$ & $2(0.6)$ & 1.0 \\
Suggested by a professional *, no. (\%) & $58(9.7)$ & $17(7.0)$ & $41(11.6)$ & 0.06 \\
Second opinion, no. (\%) & $21(3.6)$ & $7(2.9)$ & $14(3.9)$ & 0.49 \\
Intense pain, no. (\%) & $27(4.5)$ & $9(3.7)$ & $18(5.1)$ & 0.43 \\
Additional testing, no. (\%) & $157(26.3)$ & $59(24.3)$ & $98(27.6)$ & 0.36 \\
Appointment hours, no. (\%) & $8(1.3)$ & $4(1.6)$ & $4(1.1)$ & 0.59 \\
After business hours **, no. (\%) & $31(5.2)$ & $8(3.3)$ & $23(6.5)$ & 0.11 \\
Hospitalization, no. (\%) & $14(2.3)$ & $6(2.5)$ & $8(2.3)$ & 0.86 \\
Unavailable PCP ***, no. (\%) & $115(19.2)$ & $42(17.3)$ & $73(20.6)$ & 0.32 \\
Lack of upfront payment, no. (\%) & $22(3.7)$ & $13(5.3)$ & $9(2.5)$ & 0.07 \\
Geographic proximity ****, no. (\%) & $106(17.7)$ & $63(26.0)$ & $43(12.1)$ & $<0.0001$ \\
Already taken care of in this hospital, no. (\%) & $19(3.2)$ & $8(3.2)$ & $11(3.0)$ & 0.89 \\
\hline
\end{tabular}

Note: * Primary care provider, other physician, paramedical professional; ${ }^{* *}$ 20:00-08:00; ${ }^{* * *}$ primary care provider; $* * * *<15 \mathrm{~km}$ and $<20 \mathrm{~min}$ away from the hospital by personal vehicle or by mass transit. 


\subsection{Care provided at the ED}

At Bichat University Hospital, out of a total of 243 patients, 9.5\% $(n=23)$ had laboratory testing, $24.3 \%(n=59)$ had imagery, and 5.3\% $(n=13)$ had both. Together, $28.4 \%(n=69)$ of these patients received further testing. At Poitiers University Hospital, amongst the 355 patients, $11.3 \%(n=40)$ had laboratory testing, $28.2 \%(n=100)$ had imagery, and $5.9 \%(n=21)$ had both. Together, $33.5 \%(n=119)$ of these patients underwent further testing. In total, $6.2 \%(n=15)$ of Bichat patients received some form of treatment. Among the CIMU 5 patients included in the present study, 2.1\% $(n=5)$ were hospitalized after the ED stage. All of them had received laboratory and imagery exploration and some form of treatment. At Bichat, one patient left after completing the survey given by the TN but before seeing an emergency physician and could not be categorized according to the CCMU medical classification, and four did the same at Poitiers. Consequently, 242 and 351 patients were analyzed at Bichat and Poitiers hospitals, respectively. Comparison between the CCMU categories of the CIMU 5 patients at the two sites yielded no difference ( $p=0.81$ ) (Table 5 ). In $2.2 \%$ of consultations, patients triaged as CIMU 5 by the TN had a medical issue or a functional prognosis that would probably deteriorate during the ED stay (CCMU 3) or that was life-threatening (CCMU 4). All the CCMU 4 and some of the CCMU 3 patients were hospitalized and were not considered as non-urgent.

Table 5. Medical classification of the degree of severity $\left(\mathrm{CCMU}{ }^{*}\right)$ after medical examination of patients categorized CIMU $5^{* *}$ by the triage nurse.

\begin{tabular}{lcccc}
\hline \multicolumn{1}{c}{ Clinical Severity } & $\begin{array}{c}\text { Total } \\
\boldsymbol{n}=\mathbf{5 9 3}\end{array}$ & $\begin{array}{c}\text { Bichat } \\
\boldsymbol{n}=\mathbf{2 4 2}\end{array}$ & $\begin{array}{c}\text { Poitiers } \\
\boldsymbol{n}=\mathbf{3 5 1}\end{array}$ & $\boldsymbol{p}$ \\
\hline CCMU 1, no. (\%) & $399(67.3)$ & $167(69.1)$ & $232(66.1)$ & \\
CCMU 2, no. (\%) & $178(30.0)$ & $68(28.1)$ & $110(31.3)$ & \\
CCMU 3, no. (\%) & $10(1.7)$ & $4(1.7)$ & $6(1.7)$ & 0.81 \\
CCMU 4, no. (\%) & $3(0.5)$ & $1(0.4)$ & $2(0.6)$ & \\
CCMU 5, no. (\%) & $0(0.0)$ & $0(0.0)$ & $0(0.0)$ & \\
CCMU P, no. $(\%)$ & $3(0.5)$ & $2(0.8)$ & $1(0.3)$ & \\
\hline
\end{tabular}

Note: * CCMU: (French) clinical classification of emergency department patients (classification clinique médicale des urgences); ${ }^{* *}$ CMIU: The French Emergency Nurses Classification in Hospital scale (CIMU 5: no functional impairment or organic lesion justifying the use of hospital resources); CCMU 1: stable situation, abstention from complementary diagnostic or therapeutic acts; CCMU 2: stable presentation, requiring a complementary diagnostic or therapeutic act; CCMU 3: presentation likely to deteriorate without life-threatening prognosis; CCMU 4: prognosis committed, no immediate resuscitation maneuver; CCMU 5: prognosis committed, perform immediate resuscitation maneuver. CCMU P: Patient with psychological or psychiatric problems dominant in the absence of any unstable somatic pathology.

After their ED visit, $85.6 \%(n=512)$ of patients were satisfied or totally satisfied with the care they received. Additionally, $7.2 \%(n=43)$ of patients had no opinion, and $7.2 \%(n=43)$ of patients were unsatisfied or totally unsatisfied. There was no difference between both sites $(p=0.38)$. Waiting times were deemed satisfactory by $65.7 \%$ of the patients. Median waiting time was $71 \mathrm{~min}$ (interquartile range: 43 ; 94) and 73min (interquartile range: $48 ; 95)$ at the Bichat and Poitiers University Hospitals, respectively $(p=0.24)$. Level of patient satisfaction was inversely correlated to waiting time (rho $=0.61$, $p<0.0001)$.

At 15 days after ED consultation, the patients were contacted by phone. At Bichat, out of the 243 patients, $56.4 \%(n=137)$ did not respond, 3.7\% $(n=9)$ refused to respond, and $39.9 \%(n=97)$ answered our questions. In $90.7 \%(n=88)$ of cases, the ED physician had provided the care the patient desired. Out of the 88 patients, 33 reconsulted for the same issue. For 21 of them, it was after an ED physician's suggestion to consult their PCP for a follow-up consult that they did so. Regarding the patients for whom the ED physician had not provided the desired care, 9 of them consulted at another health facility $(p<0.0001)$. At Poitiers, amongst the 355 patients, $49.0 \%(n=174)$ did not answer, $5.1 \%$ $(n=18)$ refused to answer, and $45.9 \%(n=163)$ agreed to respond. Out of the 163 patients, 41 consulted 
again for the same reason, as they felt that their ailment had not improved or that the ED physician had not provided the expected care.

\section{Discussion}

\subsection{Profile and Flow Path of Patients Manageable by General Practice Consultations}

The patients who did not need to go to an ED but rather to non-emergency care were young, mostly male, and with adequate social coverage, such as has been reported in other studies [13,26]. As in the study by Piggozo [23], employees and the unemployed were the most widely represented categories. When consulting at an ED, patients used a coherent approach, as described by Gentile et al. 15 years ago [19]. This choice depends on the perception the patient has of an emergency [19]. In our study, more than half consulted less than 24 hours after symptom onset, compared to two-thirds in the study by Gentile in 2010 [26]. Additionally, the comparison between sites in our study suggests that the complaint impelling a person to consult in an ED may be influenced by hospital specificities. If the main complaint was trauma, as has been shown $[19,26]$, ED recourse was similar, whereas frequency of other complaints was site-dependent. At Bichat, for example, there were few ophthalmological or ENT-related issues. This was probably because, being in Paris, other university hospitals contain units dedicated to those specific types of pathologies. At Poitiers, where only one university hospital and one private clinic have an ED, these issues were significantly more present. The motivating factor of personal convenience has also been highlighted. Geographic proximity of the hospital was cited for both sites at a rate of $17.7 \%(n=106)$ for all studied patients, which is similar to the findings of the 2013 DREES (Research, Studies and Statistics Directorate, Ministry of Social Affaire and Health) French national survey [2]. In the present study, there existed a disparity between the sites, with a higher proportion of such patients at Bichat. This difference could be due to the shortage of general practitioners in the area surrounding Bichat. Accordingly, the number of patients having no declared principal PCP, a French health administration requirement, was significantly higher at Bichat than at Poitiers. Additionally, for those having a principal $\mathrm{PCP}$, the patients at Poitiers were significantly more likely to report that their PCP was located nearby. Other studies have described proximity as being the main factor behind the choice to consult at an ED for more than half of patients [13]. However, this reason does not appear to be the only determining factor. Indeed, although the patients consulting at Bichat were significantly more likely not to have a PCP, there was no difference between Bichat and Poitiers in the number of patients citing unavailability of their PCP as a reason to consult the ED. Finally, the consultations occurred during general practice opening hours, which in the majority of cases corresponded to weekday business hours at both Poitiers and Bichat. Other French studies have shown similar numbers, with $20 \%$ to $24 \%$ of patients mentioning a lack of PCP availability $[2,23,25]$. Only one study at a Nimes ED showed that $75 \%$ of patients having had no further testing actually encountered difficulties consulting their PCP [22]. Nonetheless, our study showed that even if a patient had ready access to a general practice, they preferred to go directly to an ED, and in most cases without asking for a referral beforehand, as described by Gentile et al. [26]. One recurring reason for consulting at the ED was an expectation of getting further testing and imagery. This could be explained by the predominance of osteo-articular pathologies presenting at the ED. This reasoning has been explored in French studies such as the one conducted in 2016 at a non-teaching hospital, where it was found that $43 \%$ of consultations were motivated by a demand for imagery testing [25]. At the national level, trauma is the principal presenting pathology for ED consultations in the general population, with a rate of 36\% [2]. The 2010 Health and Social Protection survey reported that in the event of traumatic injury during the week, 9 times out of 10 the patient goes to an ED rather than to a PCP [2]. Traumatology is also the primary reason CIMU 5 patients consult at an ED, ranging from $17 \%$ to $63 \%$ depending on the study $[13,35]$. We hypothesize that the patients believe that imagery is systematic and that it is more convenient to have all further testing carried out at an ED, instead of consulting at a PCP, then getting imagery done, and finally consulting at the PCP once again. This factor could 
explain the mixed results achieved by expensive primary care units (PCUs) in attracting these types of patients [18]. It is for this reason that to alleviate the increasing use of EDs, the French Cour des Comptes suggests that non-scheduled, urban-based points of care should be encouraged, possibly by installing testing facilities in PCUs [36]. Furthermore, a recent parliamentary report recommends the facilitating access to the simpler forms of imagery and biological testing in private practices [17]. Gentile et al. demonstrated that these structures could, with the appropriate opening hours, be adapted to fulfill the needs of the population in medical service provision. On the other hand, the often-stated main motivation for consulting being the absence of up-front payment is factually unfounded. Our results suggest that this reason for consulting at an ED is only a minor factor. Nonetheless, at Bichat this reason was stated more often than at the Poitiers $\mathrm{CHU}$ in non-severe patients at a rate higher than for the general French population [2]. Poverty, therefore, seems to be a relevant factor. The great majority of patients consulted during business hours regardless of whether or not they had access to a PCP. It was, therefore, not a scheduling issue that was blocking those patients' access to a PCP. Our results suggest that up to $69.0 \%$ of these patients would be interested in another solution than the ED if access to testing facilities were available during the same hours of the day. Most of the CCMU 2 patients, who represented $28.1 \%$ of the studied patients, could have consulted their PCP. For these patients, further testing could have been delayed and performed in private practices. Instead, they were done on site because of easy access to testing facilities.

In total, $88.0 \%$ of patients consulting an ED of their own volition are categorized as CCMU 1 or 2 according to the 2002 DREES national survey. Expected savings when compared to a non-urgent care structure are, therefore, substantial, but they cannot be achieved without ensuring the geographic proximity of private practice points of care to testing facilities. Indeed, our results showed that 5 patients (2.1\%) who were correctly triaged as CIMU 5 by the TN required hospitalization. They showed clinical signs of severity and had normal vital signs. Sending CIMU 5 patients to their PCPs would be a loss of time, and in a few cases of chances of receiving proper care. This is why all CIMU 5 patients must be examined by an emergency physician. A 2003 law enacted in the United States follows the same reasoning-it is forbidden to send home or re-orient a patient solely on triage [1]. Patient satisfaction for ED physicians was $85.6 \%$, which shows that the studied EDs have managed to cope with this demand for nonscheduled care.

\subsection{What Solutions Could Be Feasible to Optimally Offer Care for These Patients?}

All of these data suggest three possible flow paths for the care of CIMU 5 patients. If we consider that these patients must be cared for in an ED environment, then the development of specific fast tracks to welcome them should be encouraged. The corresponding sector must be isolated from the rest of the ED with specific management by a designated physician, so as to avoid disrupting the care of the most severe patients. This type of management could also be done by the PCPs, as long as they have easy access to testing facilities in accordance with patient needs. We speculate that most of the patients who are classified CIMU 5 would receive the same treatment in other university hospitals because they usually do not require further exploration, laboratory testing, or imaging. A small proportion of patients would be referred to hospital after examination and would likely be classified as CCMU 3 or higher. On the other hand, if these patients come directly to the ED, it is impossible to redirect them to another PCP before the medical consultation, since some of the CIMU 5 patients would then classified by the emergency physician as CCMU 3 or higher. In reality, and even if the patient does not require further testing, that patient would not spontaneously come to such a structure if it were lacking the potential for medical testing [26], possibly diminishing the flow of patients to the ED [9]. Xin concluded in a recent study that whenever possible PCPs may be called upon to devote more effort to both communication and quality of care to improve patients' health outcomes and satisfaction and to reduce non-urgent ED use [37]. Finally, a third path could be laid out by developing hybrid organizations between an ED and one or several general practices. A recent study demonstrated that this solution could be an interesting alternative [38]. Such organizations have been evaluated abroad, 
such as in Switzerland [39] and Belgium [10]. Their conclusions remain prudent and more studies of these organizations, which seem to attract patients and could help to resolve ED overcrowding, are necessary [9]. This type of management could reduce the number of consultations in EDs by $40 \%$ and yield significant improvements of time and resources [40].

Some PCPs judge these types of organizations very favorably because they steer trauma patients directly to an ED [22]. The effectiveness of these solutions cannot depend solely on EDs. Appropriate political means must be set up to resolve the problems raised in the present study. Reforms relating to the emergency system in France should be carried out at the national level. Finally, these organizations cannot impact consultations not requiring an ED in the most vulnerable or marginalized segments of the population. There is an overall increase in ED visits in Europe by people in precarious social situations, such as the homeless, migrants, and asylum seekers. It has been characterized as the result of cultural differences, poor knowledge of local healthcare systems, and language barriers [41-43]. In France, health policy specifically targeted at improving the health of migrants is not very developed and has primarily focused on the prevention of infectious diseases such as AIDS and tuberculosis [6]. Access to healthcare other than at an ED should be facilitated at a national and supranational level in Europe in order to address migrants' health needs.

\subsection{Limits}

This study is not without limitations. Firstly, one bias in our study is linked to the selection of our CIMU 5 patients. We selected only $13.9 \%$ of all CIMU 5. There were more eligible participants in Poitiers than in Bichat hospital, i.e., the smaller establishment. The language criterion was the main limitation but arguably selected those most likely to have access to a nearby PCP and to possess knowledge of the healthcare system. Usually patients who cannot speak French or English are migrants or refugees. In the Parisian area of Bichat, there are more migrants and refugees than in Poitiers. In the present study, in order to avoid a cultural bias, they were not included. Consequently, we speculate that this situation may have facilitated inclusions in the hospital at Poitiers compared to those at Bichat. Moreover, the aim of this study was to provide a possible alternative to EDs for these consultations. The problems of refugees and migrants require other political and social considerations, since they currently have little or no alternative to ED consultation. This was not the case for this study population. A future study specific to vulnerable populations should be carried out. Additionally, not all of the patients who met all of the selection criteria were able to be included by the TNs, particularly during periods of very high inflow. We speculated that in overcrowding periods, TNs are less likely to include patients. The ED of Bichat is more exposed to this situation than in Poitiers. Another potential bias is that of the test centers, considering that the urban areas presented different socio-economic makeups. Even though the surveys were anonymous, certain answers may have been influenced by fear of being judged by the caregivers. Finally, some factors associated with inappropriate ED usage were not studied. A recent study in a Japanese hospital found that having two or more prior out-of-hours ED visits in the past 3 years was identified as a factor [14].

\section{Conclusions}

This study has allowed us to demonstrate that users of non-emergency care have a coherent approach when consulting at an ED. Motivating factors for consulting at an ED rather than the PCP seem to be personal convenience, accessibility of emergency facilities, and geographic proximity. The patients are satisfied with care and this satisfaction is inversely correlated to waiting time. They cannot be turned away before having been seen by an ED physician, as at least a small portion of them will require hospitalization. It seems essential that healthcare points of entry with access to testing facilities should put them to work by either employing an internal fast track or by developing "hybrid" health structures by associating an ED with one or several local PCP structures, thereby helping to resolve ED overcrowding. 
Author Contributions: D.A.G.: conception and design of the study, analysis and interpretation of data, drafting of the article. A.R.: acquisition of data. A.C.: acquisition of data. C.C.: acquisition of data. M.G.: analysis and interpretation of data, drafting of the article. E.C.: interpretation of data, critical revision of the article for important intellectual content.

Funding: The authors declare that they have no source of funding for the research.

Acknowledgments: The authors would like to thank Jeffrey Arsham, an American medical translator, for having reviewed the English language text.

Conflicts of Interest: The authors declare having no conflicts of interest.

Consent to Publish: Participants consented to the publication of de-identified data and individual details. The manuscript does not contain individual images or videos.

Availability of Data and Material: All data analyzed during this study are included in the manuscript and supplemental files. Materials described in the manuscript, including all relevant raw data, are freely available to any scientist wishing to use them for noncommercial purposes, without breaching participant confidentiality. For more details, please contact the corresponding author.

\section{Abbreviations}

CCMU French clinical emergency department classification (Classification Clinique des Malades aux Urgences)

CIMU French Emergency Nurses Classification in Hospital scale, CIMU (Classification Infirmière des Malades aux Urgences)

ED emergency department

ENT ear, nose, and throat

PCP primary care provider

SFMU French Emergency Medicine Society

TN triage nurse

Appendix A. The French Emergency Nurses Classification in Hospital scale, Classification Infirmière des Malades aux Urgences (CIMU)

\begin{tabular}{|l|l|l|}
\hline Triage & Description & Action \\
\hline 1 & Immediately life-threatening. & $\begin{array}{l}\text { Actions focused on support of one or more } \\
\text { vital functions. } \\
\text { Immediate medical and paramedical } \\
\text { intervention. }\end{array}$ \\
\hline 2 & $\begin{array}{l}\text { Marked impairment of a vital organ or } \\
\text { imminently life-threatening or functionally } \\
\text { disabling traumatic lesion. }\end{array}$ & $\begin{array}{l}\text { Actions focused on treatment of the vital } \\
\text { function or traumatic lesion. } \\
\text { Immediate paramedical and medical } \\
\text { intervention within 20 min. }\end{array}$ \\
\hline 3 & $\begin{array}{l}\text { Functional impairment or organic lesions likely } \\
\text { to deteriorate within 24 h or complex medical } \\
\text { situation justifying the use of several } \\
\text { hospital resources. }\end{array}$ & $\begin{array}{l}\text { Multiple actions focused on diagnostic } \\
\text { evaluation and prognostic evaluation in } \\
\text { addition to treatment. } \\
\text { Medical intervention within } 60 \text { min } \pm \\
\text { followed by paramedical intervention. }\end{array}$ \\
\hline 4 & $\begin{array}{l}\text { Stable, noncomplex functional impairment or } \\
\text { organic lesions, but justifying the urgent use of } \\
\text { at least one hospital resource. }\end{array}$ & $\begin{array}{l}\text { Consult with limited diagnostic or } \\
\text { therapeutic procedures. } \\
\text { Medical intervention within } 120 \text { min } \pm \\
\text { followed by paramedical intervention. }\end{array}$ \\
\hline 5 & $\begin{array}{l}\text { No functional impairment or organic lesion } \\
\text { justifying the use of hospital resources. }\end{array}$ & $\begin{array}{l}\text { Consult with no diagnostic or therapeutic } \\
\text { procedure. } \\
\text { Medical intervention within 240 min. }\end{array}$ \\
\hline$*$ & $\begin{array}{l}\text { Intense symptom or abnormal vital parameter } \\
\text { justifying rapid corrective action. }\end{array}$ & $\begin{array}{l}\text { Specific action within 20 min. } \\
\text { The star can complete a triage 3 or 4. }\end{array}$ \\
\hline
\end{tabular}




\section{Appendix B. Survey Distributed to the Included CIMU 5 Patients}

Family name:

First name:

Sex:

$\square$ Female

$\square$ Male

Birthday:

Phone:

City/Town of residence:

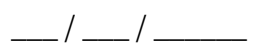

1 What is your social security coverage?

Social security insurance

Complementary health coverage

Special social security (CMU, AME)

None

2 Do you have a General Practitioner/Family Physician?

Yes, in which city is your GP?

No

3 What is your profession?

Farmer, agricultural worker

Craftsman, merchant, manager

Executive, intellectual profession

Intermediate professions

Employee

Unskilled laborer

Retired

No professional activity

Student

4 How many times a year do you visit an emergency department?

5 Reason for consultation at the emergency department

6 Date of onset of the troubles?

7 Have you ever previously consulted for the same reason? $\square$ Yes $\square$ No

If yes, how long ago?

If so, at your doctor's office?

Yes

No, where did you consult?

Have you tried to treat yourself? $\square$ Yes $\square$ No

8 Why did you choose the emergency department?

Proximity to home or work

Schedule compatibility with my activity

Attending GP unavailable

The appointment proposed by my doctor was not convenient for me

I have moved and I have not yet found a doctor

I don't have a GP

I am on business travel, so I do not have access to my GP

After advice from my GP or another health professional (another doctor, physiotherapist, nurse, etc.)

I wanted another medical opinion, in addition to that of my GP

I would like to have direct advice from a specialist 
I thought I would need additional tests (blood test, imagery, etc.)

I thought I would have to be hospitalized

I'm being followed in the hospital

I chose to consult at the emergency department because it is well known that it is the quickest

I cannot pay any upfront fees

Other:

\section{Appendix C. French Clinical Emergency Department Classification, Classification Clinique des Malades aux Urgences (CCMU)}

\begin{tabular}{|l|l|}
\hline Classification & Description \\
\hline CCMU 1 & Stable situation, abstention from complementary diagnostic or therapeutic act \\
\hline CCMU 2 & Stable situation, perform a complementary diagnostic or therapeutic act \\
\hline CCMU 3 & Situation likely to deteriorate without being life-threatening \\
\hline CCMU 4 & Prognosis committed, no immediate resuscitation maneuver \\
\hline CCMU 5 & Prognosis committed, perform immediate resuscitation maneuver \\
\hline CCMU P & $\begin{array}{l}\text { Patient with psychological or psychiatric problems dominant in the absence of any } \\
\text { unstable somatic pathology }\end{array}$ \\
\hline CCMU D & Patient dies at the entrance to the emergency \\
\hline
\end{tabular}

From: Afilal [34].

\section{Appendix D. Informed Consent}

Dear Sir or Madam,

You are going to see an emergency physician in the fast track unit of the emergency department. A study aimed at evaluating the motivations of patients without life-threatening conditions who use an emergency department is being conducted in the emergency departments of the Bichat-Claude-Bernard and Poitiers University Hospitals. We have also added a patient satisfaction survey. This study is focused on the improvement of the quality of care in the fast track unit of our emergency department. If you agree to take part in it, you will be required to answer this survey during the waiting time after having seen the triage nurse and before seeing the emergency physician. In this survey, the following data are collected:

- $\quad$ Sociodemographic categories

- $\quad$ Medical administrative information

- $\quad$ Motivation to consult in the emergency department

- Patient satisfaction

The processing of all these data will be strictly confidential and anonymous.

The Emergency Department of Bichat has specific software intended for patient management. The registered information is reserved for the emergency department and can only be communicated to the following addresses:

- $\quad$ Dr Aiham Daniel GHAZALI, main investigator, Emergency Department of Bichat Hospital

- $\quad$ Dr Arnaud CHAUDET, Emergency Department of Poitiers Hospital

You will be contacted by phone 15 days after your ED visit, between 18:00 and 20:00, to collect information about your status once having left the ED and your satisfaction level.

Dr GHAZALI is at your disposal to provide any information which you might consider useful.

According to articles 39 and following articles of law $n$ 78-17 of January 6, 1978, modified in 2004, relative to computing, to files, and to personal liberties, any person can obtain the communication, and where necessary, rectification or deletion of their corresponding information, by contacting Dr Aiham Daniel Ghazali (Bichat Hospital, 46 rue Henri Huchard, 75018 Paris).

If you agree to participate in the present survey, a copy of this document will be provided to you and a second signed copy will be given to the emergency physician with the questionnaire.

\section{References}

1. Durand, A.C.; Gentile, S.; Devictor, B.; Palazzolo, S.; Vignally, P.; Gerbeaux, P.; Sambuc, R. ED patients: How non-urgent are they? Systematic review of the emergency medicine literature. Am. J. Emerg. Med. 2011, 29, 333-345. [CrossRef] [PubMed]

2. Résultats de l'enquête nationale auprès des structures des urgences hospitalières. 2013. Available online: http://drees.solidarites-sante.gouv.fr/etudes-et-statistiques/publications/les-dossiers-de-la-drees/dossierssolidarite-et-sante/article/resultats-de-1-enquete-nationale-aupres-des-structures-des-urgences (accessed on 12 September 2019). 
3. Sarría-Santamera, A.; Hijas-Gómez, A.I.; Carmona, R.; Gimeno-Feliú, L.A. A systematic review of the use of health services by immigrants and native populations. Public Health Rev. 2016, 37, 28. [CrossRef] [PubMed]

4. Müller, M.; Klingberg, K.; Srivastava, D.; Exadaktylos, A.K. Consultations by Asylum Seekers: Recent Trends in the Emergency Department of a Swiss University Hospital. PLoS ONE 2016, 11, e0155423. [CrossRef] [PubMed]

5. Ruud, S.E.; Aga, R.; Natvig, B.; Hjortdahl, P. Use of emergency care services by immigrants-A survey of walk-in patients who attended the Oslo Accident and Emergency Outpatient Clinic. BMC Emerg. Med. 2015, 15, 25. [CrossRef] [PubMed]

6. Mladovsky, P. Migration and Health in the EU, Research Note for the European Commission, DG Employment and Social Affairs; Employment, Social Affairs and Equal Opportunities: London, UK, 2007.

7. Berchet, C. Health care utilisation in France: An analysis of the main drivers of health care use inequalities related to migration. Rev. Epidemiol. Sante Publique 2013, 61, 69-79. [CrossRef] [PubMed]

8. Winters, M.; Rechel, B.; de Jong, L.; Pavlova, M. A systematic review on the use of healthcare services by undocumented migrants in Europe. BMC Health Serv. Res. 2018, 18, 30. [CrossRef] [PubMed]

9. Crawford, J.; Cooper, S.; Cant, R.; DeSouza, R. The impact of walk-in centres and GP co-operatives on emergency department presentations: A systematic review of the literature. Int. Emerg. Nurs. 2017, 34, 36-42. [CrossRef] [PubMed]

10. Van den Heede, K.; Quentin, W.; Dubois, C.; Devriese, S.; Van de Voorde, C. The 2016 proposal for the reorganisation of urgent care provision in Belgium: A political struggle to co-locate primary care providers and emergency departments. Health Policy 2017, 121, 339-345. [CrossRef] [PubMed]

11. Bardelli, P.; Kaplan, V. Non-urgent encounters in a Swiss medical emergency unit. Swiss Med. Wkly. 2013, 143, w13760. [CrossRef] [PubMed]

12. Baubeau, D.; Carrasco, V. Ministère de la Solidarité de la Santé et de la Protection Sociale. Direction de la Recherche des Etudes de l'Evaluation et des Statistiques. (D.R.E.E.S.). Paris. FRA. Motifs et trajectoires de recours aux urgences hospitalières. Etudes Result 2003, 215, 1-12. Available online: https://drees.solidarites-sante.gouv.fr/etudes-et-statistiques/publications/etudes-et-resultats/article/ motifs-et-trajectoires-de-recours-aux-urgences-hospitalieres (accessed on 12 September 2019).

13. Aissaoui, L. Consultations spontanées aux urgences du centre hospitalier de Givors étude monocentrique, observationnelle, du 1er au 28 mars 2011 des patients non hospitalisés durant les heures ouvrables des cabinets médicaux analyse des caractéristiques sociologiques des consultants, de leurs motifs de recours et évaluation de leur satisfaction de service. Lyon. 2014. Available online: https://books.google.fr/books/about/ Consultations_spontan\%C3\%A9es_aux_urgences_d.html?id=gkvMoAEACAAJ\&redir_esc=y (accessed on 12 September 2019).

14. Miyazawa, A.; Maeno, T.; Shaku, F.; Tsutsumi, M.; Kurihara, H.; Takayashiki, A. Inappropriate use of the emergency department for non-urgent conditions: Patient characteristics and associated factors at a Japanese hospital. J. Gen. Fam. Med. 2019, 20, 146-153. [PubMed]

15. Redstone, P.P. Non-urgent use of the emergency department. J. Ambul. Care Manag. 2008, 31, 370-376. [CrossRef] [PubMed]

16. Sempere-Selva, T.; Peiro, S.; Sendra-Pina, P.; Martinez-Espin, C.; Lopez-Aguilera, I. Inappropriate use of an accident and emergency department: Magnitude, associated factors, and reasons-An approach with explicit criteria. Ann. Emerg. Med. 2001, 37, 568-579. [CrossRef] [PubMed]

17. Mesnier, T. Assurer le premier accès aux soins-Organiser les soins non programmés dans les territoires. 2018. Available online: https://solidaritessante.gouv.fr/IMG/pdf/rapport_snp_vf.pdf (accessed on 12 September 2019).

18. Cohen, L.; Genisson, C.; Savary, R.P. Sénat. Paris. FRA. Rapport d'information sur les urgences hospitalières. 2017. Available online: https://www.senat.fr/rap/r16-685/r16-6851.pdf (accessed on 12 September 2019).

19. Gentile, S.; Amadeï, E.; Bouvenot, J.; Durand, A.C.; Bongiovanni, I.; Haro, J.; Giraud, C.; Sambuc, R. Attitudes et comportement des usagers face à une urgence réelle ou ressentie. St. Publique 2004, 16, 63. [CrossRef] [PubMed]

20. Toulemonde, C. Évaluation de l'offre de soins primaires des médecins et des urgences médicales de Paris et évolution prévue à 2 et 5 ans dans le cadre de l'étude Demomed75. Thèse d'exercice de médecine générale. Paris 6 Pierre et Marie Curie. 2015. Available online: https://pdfs.semanticscholar.org/1be4/ 2be0e6e651c3ff7fabfc6317db9ec8dc0acb.pdf. (accessed on 12 September 2019). 
21. Atenstaedt, R.; Gregory, J.; Price-Jones, C.; Newman, J.; Roberts, L.; Turner, J. Why do patients with non-urgent conditions present to the Emergency Department despite the availability of alternative services? Eur. J. Emerg. Med. 2015, 22, 370-373. [CrossRef] [PubMed]

22. Sagnes-Raffy, C. Observatoire Régional des Urgences Midi-Pyrénées (O.R.U.M.I.P.). Étude des déterminants conduisant les patients qui ne relèvent pas de l'urgence médico-vitale à se présenter dans un service d'urgence public ou privé plutôt que de faire appel à la médecine de ville. RECTO VERSO. Toulouse. 2004. Available online: https://www.orumip.fr/wp-content/uploads/2011/11/RV6.pdf (accessed on 12 September 2019).

23. Pigozzo, C. Étude prospective et analyse du profil et motivations des patients consultant aux urgences pour des motifs relevant de la médecine générale. Thèse d'exercice de médecine générale. Montpellier. 2014. Available online: https://bdsp-ehesp.inist.fr/vibad/index.php?action=getRecordDetail\&idt=483061 (accessed on 12 September 2019).

24. Le Roux, S. Les patients CCMU1 consultent-ils au service des urgences du CHU de Nîmes suite à des difficultés d'accès aux soins primaires? Thèse d'exercice de médecine générale. Montpellier. 2013. Available online: https://books.google.fr/books/about/Les_patients_CCMU1_consultent_ils_au_ser.html?id= 5IrLuQEACAAJ\&redir_esc=y (accessed on 12 September 2019).

25. Beauné, $n$. Quels sont les déterminants de consultations spontanées au service des urgences des patients adultes ayant dejà consulté un médecin généraliste pour le même motif? étude quantitative menée au service des urgences du centre hospitalier Alpes Léman. Thèse d'exercice de médecine générale. Lyon. 2016. Available online: https://www.worldcat.org/title/quels-sont-les-determinants-de-consultations-spontanees-au-servicedes-urgences-des-patients-adultes-ayant-deja-consulte-un-medecin-generaliste-pour-le-meme-motifetude-quantitative-menee-au-service-des-urgences-du-centre-hospitalier-alpes-leman/oclc/951383097 (accessed on 12 September 2019).

26. Gentile, S.; Vignally, P.; Durand, A.C.; Gainotti, S.; Sambuc, R.; Gerbeaux, P. Non-urgent patients in the emergency department? A French formula to prevent misuse. BMC Health Serv. Res. 2010, 10, 66. [CrossRef] [PubMed]

27. Saryoul, S. Influence de la précarité sur le choix des urgences ou du médecin généraliste pour une consultation de soins primaires. Thèse d'exercice de médecine générale. Dijon. 2016. Available online: file://D:/Users/g-bjn-5054263/Downloads/SARYOUL_THESEMED.pdf (accessed on 12 September 2019).

28. Shaw, E.K.; Howard, J.; Clark, E.C.; Etz, R.S.; Arya, R.; Tallia, A.F. Decision-making processes of patients who use the emergency department for primary care needs. J. Health Care Poor Underserved 2013, 24, 1288-1305. [CrossRef] [PubMed]

29. Wang, H.; Nejtek, V.A.; Zieger, D.; Robinson, R.D.; Schrader, C.D.; Phariss, C. The role of charity care and primary care physician assignment on ED use in homeless patients. Am. J. Emerg. Med. 2015, 33, 1006-1011. [CrossRef] [PubMed]

30. Taboulet, P.; Moreira, V.; Haas, L.; Porcher, R.; Braganca, A.; Fontaine, J.P.; Poncet, M.C. Triage with the French Emergency Nurses Classification in Hospital scale: Reliability and validity. Eur. J. Emerg. Med. 2009, 16, 61-67. [CrossRef] [PubMed]

31. Fays Duet, M. Enquête DémoMed 75: Évaluation de l'offre de soins primaires à Paris et évolution prévisible dans 2 et 5 ans. Résultats sur le 18ème arrondissement. Thèse d'exercice de médecine générale. Paris 7 Denis Diderot. 2014. Available online: http://www.bichat-larib.com/publications.documents/4698_FAYS-THESE. pdf?bcsi_scan_08276ca4327756e4=1 (accessed on 12 September 2019).

32. Données statistiques sur la démographie des professionnels de santé (PS) libéraux. L'Assurance Maladie. 2017. Available online: https://www.ameli.fr/l-assurance-maladie/statistiques-et-publications/ donnees-statistiques/professionnels-de-sante-liberaux/demographie/effectifs-et-densite.php (accessed on 12 September 2019).

33. Sanz, M.; Noguerol, B.; Sanz-Sanchez, I.; Hammerle, C.H.; Schliephake, H.; Renouard, F.; Steering Committee. European Association for Osseointegration Delphi study on the trends in Implant Dentistry in Europe for the year 2030. Clin. Oral Implant. Res. 2019, 30, 476-486. [CrossRef] [PubMed]

34. Afilal, M.; Yalaoui, F.; Dugardin, F.; Amodeo, L.; Laplanche, D.; Blua, P. Emergency department flow: A new practical patients classification and forecasting daily attendance. IFAC PapersOnLine 2016, 49, 721-726. [CrossRef] 
35. Nosjean, C. Quels sont les déterminants de l'accès aux soins primaires en pré-hospitalier des consultations de médecine générale aux urgences de Fontenay Le Comte? étude descriptive, prospective, monocentrique, réalisée entre février 2016 et septembre 2016. Thèse d'exercice de médecine générale. Nantes. 2017. Available online: file://D:/Users/g-bjn-5054263/Downloads/nosjeanMED17.pdf (accessed on 12 September 2019).

36. Cour des Comptes. Paris. FRA. Les urgences hospitalières: Une fréquentation croissante, une articulation avec la médecine de ville à repenser. In Rapport sur l'application des lois de financement de la sécurité sociale; Cour des Comptes: Paris, France, 2014; pp. 359-387. Available online: https:/www.ccomptes.fr/sites/default/ files/EzPublish/rapport_securite_sociale_2014_urgences_hospitalieres.pdf (accessed on 12 September 2019).

37. Xin, H. Patient Dissatisfaction with Primary Care and Non-urgent Emergency Department Use. J. Ambul. Care Manag. 2019, 42, 284-294. [CrossRef] [PubMed]

38. Greenfield, G.; Ignatowicz, A.; Gnani, S.; Bucktowonsing, M.; Ladbrooke, T.; Millington, H. Staff perceptions on patient motives for attending GP-led urgent care centres in London: A qualitative study. BMJ Open 2016, 6, e007683. [CrossRef] [PubMed]

39. Chmiel, C.; Wang, M.; Sidler, P.; Eichler, K.; Rosemann, T.; Senn, O. Implementation of a hospital-integrated general practice-A successful way to reduce the burden of inappropriate emergency-department use. Swiss Med. Wkly. 2016, 146, w14284. [CrossRef] [PubMed]

40. Cleary, A.; Zeller, R.; Maguire, C.; Goh, S.; Shortt, N. Do all adult orthopaedic injuries seen in emergency departments need to attend fracture clinic? A Queensland multicentred review. Emerg. Med. Australas. EMA 2017, 29, 658-663. [CrossRef] [PubMed]

41. Norredam, M.; Nielsen, S.S.; Krasnik, A. Migrants' utilization of somatic healthcare services in Europe-A systematic review. Eur. J. Public Health 2010, 20, 555-563. [CrossRef] [PubMed]

42. Norredam, M.; Mygind, A.; Nielsen, A.S.; Bagger, J.; Krasnik, A. Motivation and relevance of emergency room visits among immigrants and patients of Danish origin. Eur. J. Public Health 2007, 17, 497-502. [CrossRef] [PubMed]

43. Hargreaves, S.; Friedland, J.S.; Gothard, P.; Saxena, S.; Millington, H.; Eliahoo, J. Impact on and use of health services by international migrants: Questionnaire survey of inner city London A\&E attenders. BMC Health Serv. Res. 2006, 6, 153.

(C) 2019 by the authors. Licensee MDPI, Basel, Switzerland. This article is an open access article distributed under the terms and conditions of the Creative Commons Attribution (CC BY) license (http://creativecommons.org/licenses/by/4.0/). 